\title{
Health Knowledge, Attitude and Practice Among Iranian Pilgrims
}

\author{
Aminreza Tabatabaei ${ }^{1}$; Seyyed Mostafa Mortazavi ${ }^{1}$; Navvab Shamspour ${ }^{1, *}$; Naser Shushtarizadeh $^{2}$ \\ ${ }^{1}$ Hajj and Pilgrimage Health Research Center, Tehran, IR Iran \\ ${ }^{2}$ Representative of Iranian Hajj and Pilgrimage Medical Center, Madinah Almonavvarah, Saudi Arabia \\ *Corresponding Author: Navvab Shamspour, Hajj and Pilgrimage Health Research Center, Ostad Nejatollahi St., RCS Building, Tehran, IR Iran. Tel:+98-2186744114, Fax: +98-2188912476, \\ E-mail: navabshamspour@gmail.com
}

Received: June 11, 2013; Revised: January 28, 2014; Accepted: March 11, 2014

\begin{abstract}
Background: Iran has the highest number of Umrah pilgrims among Islamic countries. Health care plays a major role in fulfilling the Umrah rites. Pilgrims' health situation depends on their health knowledge, attitude, and practice (KAP).

Objectives: In this study, we aimed to determine the health KAP among Iranian Umrah pilgrims.

Patients and Methods: In this cross-sectional study, 157 Iranian Umrah pilgrims were randomly selected in Mecca, Saudi Arabia in June 2011. Data were collected using a questionnaire. The questionnaire consisted of demographic information (sex, age, degree of education, and resource of health knowledge), health knowledge (5 questions), health attitude (5 questions) and health practice (10 questions).

Results: Level of knowledge were very low in $12.1 \%$, low in $25.2 \%$, average in $38.1 \%$, good in $20.4 \%$ and very good in $4.2 \%$ of respondents. Mean and standard deviation of attitude score was $18.58 \pm 2.20$ out of 25 (ranged between 13.00 and 25.00 ). The pilgrims were given $74.2 \%$ out of total score. The Mean and standard deviation of practice score was $8.19 \pm 1.32$ out of 10 (ranged between 3 and 10 ). Although the old and low educated pilgrims had little knowledge of health tips, they had a good health attitude and practice.

Conclusions: Educational strategy to improve knowledge regarding health-related problems and to develop health practices among pilgrims is needed.
\end{abstract}

Keywords:Health Knowledge, Attitudes, Practice; Public Health Practice; Attitude

\section{Background}

The Umrah is a pilgrimage trip to Medina and Mecca in Saudi Arabia, performed by Muslims that can be undertaken during the year. In Arabic language, Umrah means "to visit a populated place." In Fiqh, Umrah means to perform Tawaf round the Kaaba and Sa'i between Al-Safa and Al-Marwah, after assuming Ihram (a sacred state), from a Miqat like Zu 'l-Hulafa, Juhfa, Qarnu 'l-Manāzil, Yalamlam, and so on. It is sometimes called the 'minor pilgrimage' or 'lesser pilgrimage', in contrast to Hajj, which is the 'major pilgrimage' and compulsory for every able-bodied Muslim who can afford it. Al-umrah al-mufradah refers to Umrah that is performed independently of Hajj (1). Iran possess one of the highest number of Umrah pilgrims among Islamic countries (2). Appropriate health status makes this religious trip easier not only to enjoy Umrah in the pleasure of Almighty Allah, but also to make maximum use of this opportunity to perform as much worship as possible. Health plays a major role in fulfilling the Umrah rites. Umrah can be physically dependent on circumstances prevailing at the time (3). This condition is dependent on knowledge, attitude, and practice (KAP) of pilgrims (3).

\section{Objectives}

In this study, we aimed to determine the health KAP among Iranian Umrah pilgrims.

\section{Patients and Methods}

In this cross-sectional study, 157 Iranian Umrah pilgrims were randomly selected from the present pilgrims in Mecca during a 3-day period in June 2011. This research project is not inconsistent by any codes of ethics in Research Ethics Committee of regional and international statements regarding this issue. The pilgrim's information remained confidential. The study was conducted in the form of a survey, with data being gathered via the questionnaire instrument consisted of demographic information (sex, age, resource of health knowledge and degree of education), health knowledge (5 questions), health attitude (5 questions) and health practice (10 questions). In knowledge section, there were 5 questions with 4 options that questioned pilgrims about the cause of constipation; back pain, and leg pain during Umrah; hazards of consuming carbonated drinks, very cold water and spices; and methods of common cold prevention. In attitude section, there were 5 questions rated according to 5-level Likert scale (strongly disagree, disagree, neither agree nor disagree, agree, strongly agree ) that questioned pilgrims about observed crossing the street, consuming of food remains, smoking, dieting during Umrah, and correct consuming of drug. In the practice section, there were 10 questions with yes/ no answers, which asked about possessing drugs, prevention of heat- 
Tabatabaei A et al.

stroke, prevention of common cold, consuming of clean water, physical fitness, daily bathing, hand washing, and overeating of food quota. Validity of the questionnaire was confirmed by experts in health science. Although we did not carry out a pilot study to test the questionnaire's validity and reliability, a reliability analysis was performed and Cronbach $\alpha$ value was 0.82 after obtaining data from the respondents. Statistical analyzes were done using SPSS software version 17.0 (SPSS Inc, Chicago, Ill, USA). The data were analyzed using t test. P value below 0.05 was considered significant.

\section{Results}

Finally, a total of 157 pilgrims participated in this study, as three questionnaires were excluded due to their defects. About $55.4 \%$ of participants were male, $59.3 \%$ were under 40 years old, and $57.8 \%$ had associate degree or lower (Table 1). Their personal health knowledge was obtained through the following routes: $35 \%$ participation in the caravan educational classes, $15 \%$ watching educational films, $16 \%$ through reading educational leaflets, $14 \%$ magazines, $10 \%$ TV and radio programs, and 10\% through other ways. Level of knowledge was very low in $12.1 \%$ of the participants, low in $25.2 \%$, average in $38.1 \%$, good in $20.4 \%$ and very good in $4.2 \%$ of respondents. Questions about hazards of consuming carbonated drinks (76.4\%) got the highest correct answers, and lowest scores came from methods of common cold prevention (15.9). Table 2 shows the frequencies of responses to each question. Mean (SD) attitude score was 18.58 (2.20) out of 25 (ranged between 13.00 and 25.00). The pilgrims were given $74.2 \%$ out of total score. This shows that the health attitude of pilgrims is positive. Table 3 presents the frequencies of responses to each question. The mean (SD) of practice score was 8.19 (1.32) out of 10 (ranged between 3 and 10). Practice scores were above average. Except for the overeating in food quota that only $25 \%$ of answers were true, other item scores were good. There was no difference between men and women regarding knowledge, attitude, and practice scores ( $\mathrm{P}>0.05)$. However, age, and degree of education have effect on knowledge. Pilgrims under 50 years old had higher mean score of knowledge than pilgrims above 50 years $(2.87 \pm 0.95$ vs. 2.01 $\pm 0.95, \mathrm{P}=0.01)$. Pilgrims with diploma and high- er degrees had a higher mean score of knowledge than persons with lower degrees $(2.90 \pm 0.15$ vs2.10 $\pm 0.14, \mathrm{P}=$ $0.001)$. There was no correlation between knowledge, attitude, and practice scores.

\begin{tabular}{lc}
\hline \multicolumn{2}{|c}{ Table 1. Sociodemographic Characteristics of Respondents ${ }^{\text {a }}$} \\
\hline Variable & Frequency, No.(\%) \\
\hline Gender & $87(55.4)$ \\
\hline Male & $70(44.6)$ \\
\hline Female & \\
Age, $\mathbf{y}$ & $3(1.9)$ \\
$<20$ & $26(16.6)$ \\
\hline $21-30$ & $57(36.3)$ \\
$31-40$ & $39(24.8)$ \\
$41-50$ & $13(8.3)$ \\
\hline $51-60$ & $7(4.5)$ \\
\hline$>61$ & \\
\hline Education & $2(1.3)$ \\
\hline Illiterate & $21(13.4)$ \\
\hline Under diploma & $62(39.5)$ \\
\hline Diploma and associate degree & $62(39.5)$ \\
\hline BA and higher & $10(6.4)$ \\
\hline No-answer & \\
\hline a Data are presented as No.(\%).
\end{tabular}

Table 2. Level of Pilgrim's Health Knowledge $(n=157)$

\begin{tabular}{lc}
\hline Characteristics & No. $(\%)$ \\
\hline Cause of constipation & $120(76.43)$ \\
\hline True & $37(23.56)$ \\
\hline False & \\
\hline Cause of back pain and leg & $57(36.30)$ \\
\hline True & $100(63.69)$ \\
\hline False & \\
\hline Hazards of consuming soft drinks & $121(77.07)$ \\
\hline True & $36(22.92)$ \\
\hline False & \\
\hline $\begin{array}{l}\text { Hazards of very cold water and } \\
\text { spices } \\
\text { True }\end{array}$ & $120(76.43)$ \\
\hline False & $37(23.56)$ \\
\hline Methods of Prevention from colds & $25(15.92)$ \\
\hline True & $132(84.07)$ \\
\hline False & \\
\hline
\end{tabular}

\begin{tabular}{lccccc}
\hline Table 3. Level of Pilgrim's Health Attitude $(\mathrm{n}=157)^{\mathrm{a}}$ & & & & \\
\hline Characteristics & Strongly Disagree & Disagree & Undecided & Agree & Strongly Agree \\
\hline $\begin{array}{l}\text { questioned pilgrims about observed } \\
\text { crossing the street }\end{array}$ & $1(0.6)$ & $4(2.5)$ & $4(2.5)$ & $23(14.6)$ & $125(79.6)$ \\
$\begin{array}{l}\text { consuming of food remains } \\
\text { smoking }\end{array}$ & $69(43.9)$ & $58(36.9)$ & $8(5.1)$ & $12(7.6)$ & $10(6.4)$ \\
dieting during Umrah & $2(1.3)$ & $2(1.3)$ & $5(3.2)$ & $25(15.9)$ & $123(78.3)$ \\
correct consuming of drug & $0(0)$ & $4(2.5)$ & $6(3.8)$ & $40(25.5)$ & $107(68.2)$ \\
\hline
\end{tabular}

\footnotetext{
${ }^{\mathrm{a}}$ Data are presented as No.(\%).
} 


\section{Discussion}

In this study, we assessed the knowledge, attitudes, and practices of health among Iranian pilgrims. Although the pilgrims of old age and low level of education had little knowledge about health subjects, they had a good health attitude and practice. There was no association among knowledge, attitude, and practice. Few studies have been down in the field of health knowledge during the Hajj. In one study in 2009, Philippe Gautret assessed knowledge of Hajj pilgrims about ARI (Acute respiratory infection) using 18 questions about symptoms and sources of contamination. Overall, the score of true responses was only $26 \%$. Scores were higher for respondents $<65$ years of age. Scores were also higher for female pilgrims. No other demographic or health factor had significant influence (4). This study, in some cases, such as the effect of age is consistent with the previous study. Also in this study, knowledge about the respiratory infectious disease was very low.

Many believe that enjoyment of health is one of the human rights, that all depends on the hygiene (5-7). The most important goals in health promotion are empowerment of individuals through public awareness and knowledge about people's health (8). So that individuals can decide to have a healthy life and avoid unhealthy and harmful behaviors. However, these studies overlook the relation between knowledge, attitude, and function. Other studies are consistent with our findings $(8,9)$. It seems that environmental conditions, health facilities during Umrah and Islam health recommendations are factors that influence our result. However, the role of knowledge in health promotion and removal of false beliefs cannot be denied. In addition to enjoyment, proper health resources and facilities, and hygienic practices are heavily influenced by knowledge and attitudes towards hygiene (10). More researches should be performed in this field.

In this study, public awareness through media and public issues was very low, and more health information was received through in person education. As many uneducated and old age pilgrims participate in Umrah trip, and most health problems during the trip is for these group, planning for health education should be a priority for this group. Educational interventions target primary health care centers, and schools are needed. Raising the educational level of old age and uneducated or under the diploma degree is important $(8,11)$.

Several limitations must be considered when interpreting our results. First, pilgrims' self-reported behaviors may have resulted in over-reporting of correct health practices. Second, there was no significant association between knowledge, attitude and practice, which may be due to the small sample size. Lastly, the cross-sectional study design makes determining causality impossible. Anyway, educational strategy to improve knowledge regarding health-related problems and to develop health practices among pilgrims is needed. Also, we recommend to look at the level of knowledge in future studies according to demographics, which may result in better understanding of the situation.

\section{References}

1. Mamdouh MN. Hajj to Umrah: From A to Z.: Amana Publications; 1996.

2. Liali.. Statistics Umrah pilgrims. 2011. Available from: http://www. iribnews.ir/MainContent.aspx?news_num=284050.

3. Al-Shehry AM, Al-Khan AA. Pre-Hajj health related advice, Makkah. Saudi Epidemiol Bull. 1999;6(4):29-31.

4. Lopez-Quintero C, Freeman P, Neumark Y. Hand washing among school children in Bogota, Colombia. Am J Public Health. 2009;99(1):94-101.

5. Gautret P, Soula G, Parola P, Brouqui P. Hajj pilgrims' knowledge about acute respiratory infections. Emerg Infect Dis. 2009;15(11):1861-2.

6. Mann J. Health and human rights: broadening the agenda for health professionals. Health Hum Rights. 1996;2(1):1-5.

7. Mann J. Human rights and the new public health. Health Hum Rights.1995;1(3):229-33.

8. Grodin MA, Annas GJ, Glantz LH. Medicine and human rights. A proposal for international action. Hastings Cent Rep.1993;23(4):8-12.

9. Nutbeam D. Health promotion international.: Oxford University Press; 1998.

10. Linden B. Protection in practice. Nurs Times. 1991;87(11):59-60.

11. Dubik-Unruh S. Peer education programs in corrections: curriculum, implementation, and nursing interventions. J Assoc Nurses AIDS Care. 1999;10(6):53-62. 